\title{
Literature review on multi-appointment scheduling problems in hospitals
}

Joren Marynissen ${ }^{\mathrm{a}, 1}$, Erik Demeulemeester ${ }^{\mathrm{a}}$

${ }^{\text {a }}$ Faculty of Economics and Business, KU Leuven, Leuven, Belgium

Key words:

OR in health services, Multi-appointment scheduling, Combination appointments, Appointment series, Integrated healthcare

Abstract

This paper presents a review of the literature on multi-appointment scheduling problems in hospitals. In these problems, patients need to sequentially visit multiple resource types in a hospital setting so they can receive treatment or be diagnosed. Therefore, each patient is assigned a specific path over a subset of the considered resources and each step needs to be scheduled. The main aim of these problems is to let each patient visit the resources in his or her subset within the allotted time to receive timely care. This is important because a delayed diagnosis or treatment may result in adverse health effects. Additionally, with multiappointment scheduling, hospitals have the opportunity to augment patient satisfaction, allowing the patient to visit the hospital less frequently. To structure the growing body of literature in this field and aid researchers in the field, a classification scheme is proposed and used to classify the scientific work on multi-appointment scheduling in hospitals published before the end of 2017. The results show that multi-appointment scheduling problems are becoming increasingly popular. In fact, multi-appointment scheduling problems in hospitals are currently gaining progressively more momentum in the academic literature.

\section{Introduction}

Due to increasing healthcare expenditures and an ever-rising demand for healthcare services, hospitals face a continuous challenge to increase the efficiency of their operations [47]. Countless attempts have therefore been made in recent years to develop new planning or patient admission techniques. As a result, large strands of literature exist on inpatient (in which patients spend the night in the hospital) and outpatient scheduling. The literature concerning these topics has also been summarized in several extensive literature reviews such as $[1,30,58]$ for outpatient scheduling and $[27,116]$ for operating room scheduling. However, when considering the scheduling of patients, papers have had to limit their scope to a single diagnostic resource type or procedure step due to complexity constraints. In reality, patients must often undergo multiple diagnostic tests, consultations and/or surgeries to be treated $[20,47,58,128,136]$.

\footnotetext{
${ }^{1}$ Tel. +3216374482

E-mail address: joren.marynissen@kuleuven.be
} 
Additionally, patients who are scheduled using a single-resource algorithm may not be available because they might still be queuing for another resource type. Moreover, if two or more departments use single-resource scheduling algorithms, patients might have to wait a substantial amount of time between consecutive appointments on two different resources. This may affect the time to treatment, which can result in negative effects on the patient's health [46].

In recent years, an increasing number of researchers started to acknowledge these problems when focusing on patient scheduling. The result is a series of research efforts to study the scheduling process on multiple resources. We refer to such attempts with the idiom multiappointment scheduling problems in hospitals (MASPHs).

MASPHs are designed to act as an umbrella for both combination appointments (in which patients need multiple appointments, preferably on the same day [17, 68]) and appointment series (in which patients need to revisit the same set of resources several times [68]). The MASPH is defined as the problem of scheduling patients who need appointments on a subset of hospital resources by bringing together all stakeholders in the scheduling process (sometimes also referred to as agents) and optimizing the scheduling process on these specific resources from a centralized perspective. These resources include diagnostic tests (e.g., CT-scan, MRIscan, PET-scan, stress test, ECG, ultrasound), operating rooms, doctors (for a consultation), chemotherapy chairs, linear accelerators in radiotherapy and treatment rooms. A complete overview of all hospital units in which multi-appointment scheduling is currently applied is provided in Section 5.1 .

Each resource type can either consist of a single server or multiple servers [135]. The required resources can also be located in a single hospital unit or in multiple hospital units. The second situation is often referred to as multi-disciplinary scheduling of patients and was partly reviewed by Vanberkel et al. [128] and Leeftink et al. [84]. However, the former paper does not focus on scheduling, but compiles an overview of the literature that considers multiple departments in general, including departments in which little or no scheduling occurs. The latter paper does focus on scheduling, but its approach, classification schemes, scope and included manuscripts do differ from this manuscript. This is mainly due to the dissimilarity in the definition of a multidisciplinary care system. In [84], the integrated scheduling problem is mainly studied from the patient's and the provider's point of view, with an overview of the different aspects of organizing a centralized planning (e.g. hierarchical level, type of system and variability) as the focal point. In contrast, the goals of this manuscript are to focus on the researcher who is faced with the scheduling problem and to provide the researcher with an overview of the most important decisions that need to be taken as well as the available choices for each decision (e.g. common methodologies and objective functions). The results and insights in [84] are hence complimentary to those of this manuscript. 
Therefore, as already mentioned, the purpose of this paper is to aid researchers in the field of multi-appointment scheduling in hospitals by structuring and classifying all scientific work related to MASPHs. As such, a complete overview of the benefits and achievements of MASPHs is given in the hope that this strand of literature can keep growing, resulting in even better care in hospitals if the research is applied in practice. The remainder of this paper follows the purposes of this review. First, we position the MASPH concept in the literature to further clarify the concept. Second, we present our method of finding and classifying scientific work. Third, we give a structured review of MASPHs in the current literature. Doing so allows us to identify the commonly researched topics, pitfalls and gaps in the existing literature.

\section{Positioning MASPHs in the literature}

To further clarify the MASPH concept, it is necessary to elucidate its relationship with other streams of literature such as the appointment scheduling literature, the integrated healthcare literature, the patient flow literature, the resource scheduling literature and the nurse rostering literature.

First, the MASPH concept can be related to the healthcare appointment scheduling literature in that it is an integral part of that literature. To be more precise, multi-appointment scheduling problems focus on a subset of the appointment scheduling problems (i.e., the problems in which not one, but multiple resources are included in the scope). Given that the first efforts in the healthcare appointment scheduling literature date to 1952 with the work of Bailey [8] and that the amount of research in this field has expanded rapidly since then [11,58], one might expect that the number of MASPHs is also quite substantial. However, most papers in the appointment scheduling literature focus on single-resource scheduling in both outpatient and inpatient scheduling problems [30, 52]. Froehle and Magazine [50] and Van de Vrugt [135], independently of each other, noted that studies that transcend the simple clinic environment are very rare. Therefore, little or no scientific foundation is available to guide schedulers in serving patients who need an appointment with multiple providers, and such patient scheduling is rarely managed from a centralized perspective [93, 136]. In some cases, the evolution towards centralized scheduling is also purposefully halted by departments that want to keep resource calendars locally [130].

Second, the link between the MASPH concept and the integrated healthcare literature is clarified. Integrated healthcare (or integrated care) refers to the process of integrating multiple healthcare services to improve the continuity of care for patients $[3,81]$. Hence, integrated care tries to create patient-centered, affordable and accessible care, especially for patients with complex conditions [127]. In this field, researchers try to eliminate the silos of information that currently exist between hospital departments or specialists [87, 123]. Such endeavors resulted in a spectrum of integrated care methods. An early example of this is focused factories (see [18, 38,121 f for examples) or specialty clinics (see [10] for an example) in which a clinic or hospital 
unit is reorganized to focus on patients with one particular diagnosis or treatment process. This allowed the standardization of care and the centralization of all required equipment in the focused factory. In the special case that scheduling is required in these focused clinics, multiappointment scheduling techniques, as discussed in this paper, can be used to reduce the time required to complete the standardized path that is created in these focused factories. A second field of study elaborates on the concept of focused factories to create one-stop shops (see [113] for an example). One-stop shops try to reform the hospital unit to create a set-up in which patients only need to visit the hospital once and receive all care on that day. It is clear that again, in the special case in which all steps of the patient's treatment path need to be scheduled on a single day, multi-appointment scheduling techniques can be applied to achieve the main goal of the one-stop shop. Other research efforts in the integrated healthcare literature focus on integrated practice units (see $[106,107]$ ) or the use of multi-disciplinary teams of physicians who collaborate to define the necessary treatment for patients (see [17] for an example). From the previous examples, we claim that multi-appointment scheduling in hospitals adds an extra dimension to the spectrum of integrated healthcare that also allows the support of existing methods to create integrated care. It is important to note that this statement only holds true when the activities in the care path need to be scheduled, which is not the case in all hospital units or services. Using the framework of Drupsteen et al. [47], the MASPH concept can be classified as a functional integration method. In the integrated healthcare literature, special emphasis is also put on proving the effectiveness of integrated care [87] because in practice, not all integrated care methods proposed by researchers lead to statistically significant improvements in the results [49]. This also directly translates to MASPHs, for which researchers need to scientifically prove that their approach to multi-appointment scheduling works in practice as well.

Third, as discussed before, the focus of this review lies on those problems for which the patient needs to visit multiple resources in the scheduling problem. However, not all hospital units, doctors or resources rely on scheduling. As a result, a distinction between the MASPH concept and the patient flow literature is required. In the patient flow literature, researchers often try to optimize the way in which patients consume a set of predefined resources [60]. However, when doing so, patients do not require an appointment. Instead, patients start queuing for the next resource as soon as their demand for service on the previous resource has been satisfied. In other words, other than admission planning, no scheduling occurs. The goal in these problems is to reduce the patient wait time, increase the patient throughput or align the capacity of resources with the demand for services [60]. It is important to note that MASPHs cannot be seen as completely separate from patient flow problems. Hospital units share, for example, resources with other departments such that the clinical pathway of a patient can be a combination of those resources for which an appointment is needed (e.g., consultation) and those resources for which a queuing principle is applied. When the actual set of resources is larger than the set of resources that require scheduling, integrated scheduling techniques may still be applicable. 
Admission planning techniques (e.g., $[9,67,69,80,113,122,133]$ ) can be applied in an MASPH context if schedulers need to determine when to admit patients to the hospital. When studying a hybrid problem, researchers need to be aware that the performance may no longer be optimal from a centralized point of view. A full review of the connection between patient flow and scheduling techniques is thus a valuable addition for the healthcare literature but would dilute our focus from the scheduling process. As our goal is to provide an overview of all available literature on MASPHs for researchers in this field, we decided not to include the hybrid problems in this review.

Fourth, referring to the definition of the MASPH concept, it is clear that it shares a high level of similarity with flow-shop, job-shop and open-shop scheduling problems. In a job-shop scheduling problem, jobs need to visit all machines, following a predetermined fixed sequence [19]. In an open-shop problem, the sequence in which jobs must visit machines is fully flexible, and in a flow-shop problem, all jobs follow the same route through the shop [19]. If the scope of the MASPH is restricted to only planning and sequencing patients on hospital resources, then the MASPH can be described as a job-shop, flow-shop or open-shop scheduling problem, depending on the type of precedence constraints. Examples of the latter can be found in Azadeh et al. [5], Vermeulen et al. [131] and Burdett and Kozan [22].

Fifth, it is important to note that in addition to the doctors who organize consultations, other types of hospital staff (e.g., nurses) are not incorporated in the set of considered resources because we only focus on those resources for which a hospital might use an appointment book. However, this does not imply that nurses and other staff are not relevant in the patient scheduling setting. In fact, the opposite holds true. For example, in the case of a diagnostic resource, a nurse or other member of staff is needed to operate the diagnostic machine. Workload balancing and shift planning are consequently essential to patient scheduling as patients can only be scheduled when a nurse or other staff member is allocated to the diagnostic resource; however, excessive patient scheduling may result in overtime for the nurses. Nurse shift planning has already been summarized in other reviews such as [13, 25, 29].

\section{The decision level of an MASPH}

In the healthcare literature, three levels of decision making are defined: strategic, tactical and operational. The division of these three levels of planning was first proposed by Anthony [2] for manufacturing purposes in 1965 [2, 62] and has since been widely used in the healthcare literature as a framework for classifying healthcare-related scientific work [68]. First, the strategic level addresses long-term and structural decision making [68]. For patient scheduling, this implies that hospital units need to make a decision on the patient mix (the volume and composition of patient groups that the hospital unit serves) [68] and how many resources to acquire and where to locate them in order to serve all patient groups. For example, Bowers et al. [16] develop a decision tool to help a diagnosis and treatment center find the optimal capacity 
level based on the predicted demand levels. A second example can be found in both Burdett and Kozan [23] and Burdett et al. [24], who propose a system-wide analysis to determine the number of patients of each patient group that can be treated. Second, on the tactical decision level, decisions made on the strategic level are translated into guidelines that facilitate operational planning decisions $[62,68]$. Healthcare planners can allocate capacity over the available resources to patient groups [83]. Bikker et al. [14] illustrate this in a radiotherapy setting by aligning the time slots for consultations with the radiation treatment. Third, the operational decision level involves the day-to-day scheduling of patients and is divided into the offline (scheduling requests that arrive before the appointment day) and online operational levels (reacting to events that could not have been foreseen).

It is clear that all decision levels are important when focusing on multi-appointment scheduling. However, not all decision levels are equally relevant for the purposes of this review. Indeed, as a scheduling process takes the capacity of resources as a given and tries to allocate the requests of patients to the appointment books (considering the necessary constraints), MASPHs need to be classified as problems on the operational decision level. This does not imply that both tactical and strategic papers are not relevant for the operational level. As discussed before, both levels define the capacity on the operational level; thus, optimization must start at the strategic level to achieve a global optimum on the operational level. One way to achieve the global optimum would be to reserve capacity on the tactical level for patients who need multiple resources. Examples of this strategy in an oncology pathway can be found in [14, 59]. Nevertheless, because these problems tackle different research questions and to avoid diluting the focus of this manuscript, it was decided to include only problems on the operational decision level in this review.

\section{Literature search method}

We performed an initial search on the Web of Science and Scopus databases, using the search string “( (multi-appointment OR integrated OR holistic) AND ( healthcare OR patient) AND scheduling )". The resulting papers were first checked to see if they matched the scope of this review. For the purposes of this research, papers were selected on the basis of the following two criteria. First, the selected papers need to consider multiple resource types. Papers that consider single-resource scheduling were excluded from the review. The same applies to papers that consider a single resource type that has to be revisited a number of times. We excluded the latter category of papers as scheduling such appointments does not share the same level of complexity as taking multiple resources into account. The latter holds true because these scheduling problems only involve one resource calendar and no coordination between calendars is required. Scheduling appointment series on single resources is mostly applied in an oncology department as patients need to receive chemotherapy or radiotherapy multiple times. As appointment series on single resources may be relevant for the interested researcher in oncology, we included a 
short overview of such problems in Section 5.1. Second, at least a subset of all patients needs to be scheduled on a minimum of two different resource types. When patients flow from one resource to the next, a new appointment is needed on the second resource. This distinguishes the topic of this paper from the patient flow literature and the patient admission literature. To keep the content in line with the scope of this paper, we decided to exclude scheduling problems in research areas other than patient scheduling in hospitals.

Figure 1: Scatterplot depicting the selected papers and the year in which they were published. MASPHs are clearly a growing topic in the healthcare literature. The dotted line indicates the best fitting linear curve $\left(R^{2}=52.44 \%\right)$. No papers on the topic were published before 1995 .

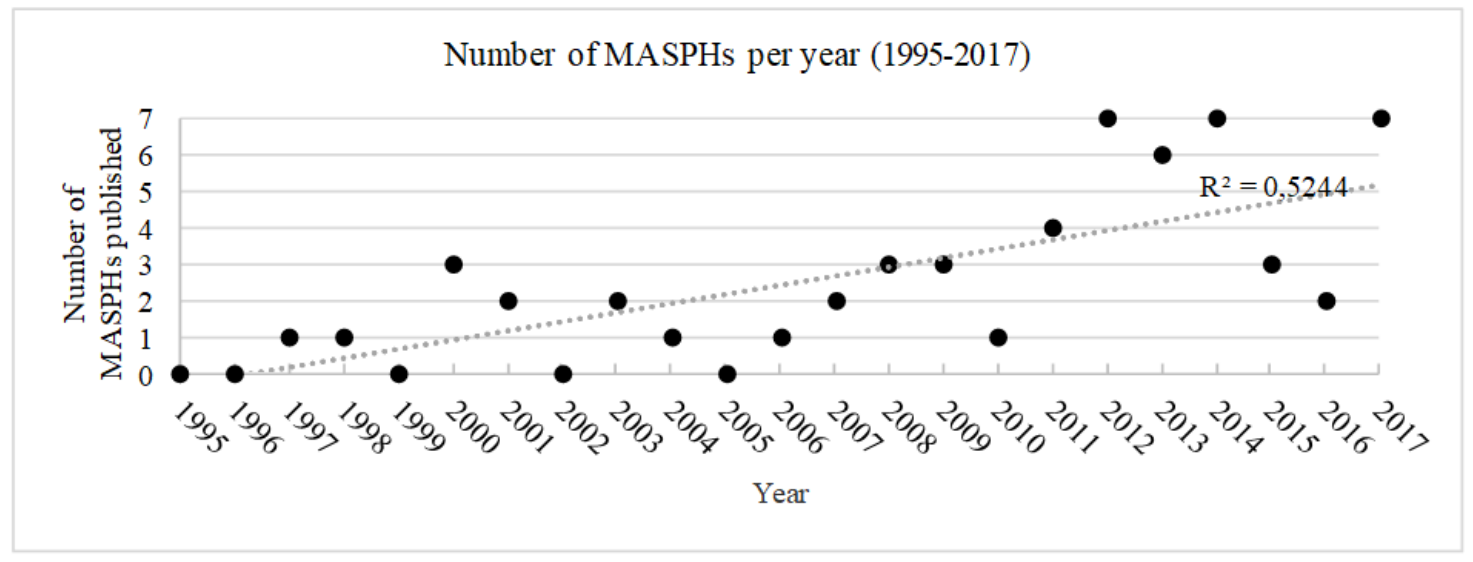

Table 1: Classification of the selected scientific work according to type.

\section{Type of scientific work}

Paper in peer-reviewed journal

Conference proceeding

Book chapter

\section{References}

$[4,5,6,17,22,28,31,32,36,39,42,43,44,45,48,52$, $56,63,65,66,74,76,79,82,85,86,89,92,96,99$, $102,105,111,119,124,129,131,134,138]$ $[15,40,41,61,75,77,78,97,100,110,114,130,137]$

$[64,88,98,101]$

Starting from this initial set of papers, we reviewed both the papers that cited and that were cited by this initial set of papers. Papers (both published and unpublished) obtained by personal communication were also added if they matched the aforementioned criteria. Both peerreviewed papers and conference proceedings were included in the review. After investigating whether each paper matched the scope of this research paper, 56 of the 481 reviewed papers were selected for inclusion, all of which were published between 1995 and 2017. Table 1 and Table 2 provide more information on the type of scientific work that was included. No related work was found that can be classified as an MASPH prior to 1995. Figure 1 proves that the topic is becoming increasingly popular in the healthcare literature. The remainder of this paper focuses on classifying the set of papers mentioned in Table 1 using different perspectives. This will help current researchers quickly find papers that are tailored to their needs. It will also aid 
new researchers in quickly learning about the field and discovering which topics have been well researched. With this goal in mind, we propose to enumerate the classification fields in the order in which they should be tackled by researchers when developing a new multi-appointment scheduling model or method. These classification fields are as follows:

- Step 1: Choosing a scope (Section 5)

- Step 2: Choosing what to optimize (Section 6)

- Step 3: Choosing how to optimize (Section 7)

- Step 4: Applying and validating the model (Section 8)

Table 2: Classification of the papers according to type of journal

Type of peer-reviewed journal

General OR journal

Specialized OR journal

Operations/management focused healthcare $[5,6,17,36,48,56,82,85,92,96,99,105$, journal

Clinically focused healthcare journal

Other journals

Scientific work not published in peer-reviewed paper

\section{References}

$[22,31,32,52,86,89,119,129,134]$

$[4,28,39,44,63,74]$

\section{Choosing a scope}

When developing a multi-appointment scheduling method or model, the first set of decisions to be made is related to the setting of the problem. In this section, we therefore elaborate on the different hospital departments in which MASPHs can be found, the resources that are usually included in the problem and the patient mix that is used when studying MASPHs.

\subsection{Hospital department}

Multi-appointment scheduling can be applied in several hospital departments, and the scheduling problems that arise in each of these departments are, not surprisingly, significantly different. Therefore, this section provides an overview of all departments in which MASPHs can be found in the current literature and a short description of the characteristics of the scheduling problem in each department. Table 3 provides a classification of the included papers 
related to the hospital unit on which they focus. Papers that are not directly classifiable into a single hospital department or do not use a specific department are labelled as general hospital. These papers often focus on general multi-resource scheduling problems in hospitals and do not refer to a particular application. The purpose is to propose a methodological framework for practitioners that can be used as a foundation when developing case-specific problem solutions. Froehle and Magazine [50] propose, for example, the Clinic Operations Management System. This conceptual framework aims to consider all aspects of multi-resource patient scheduling, including tracking patients during their visit and optimizing the clinic plan. Another example of such a strategy can be found in Rezaeiahari and Khasawneh [111] in which the authors discuss an approach to schedule appointments for medical tourists. As these patients, by definition, need to travel large distances in order to be treated, their goal is to provide all necessary care in one visit. Other than the generic hospital setting, four specific departments in which MASPHs can be found in the healthcare literature are elaborated upon below.

\section{Table 3: Classification based on hospital department}

\begin{tabular}{ll}
\hline Hospital department & References \\
\hline \multirow{2}{*}{ General hospital } & {$[4,36,39,43,44,48,52,61,63,64,74,75,76,77,89$,} \\
& $96,97,98,105,111]$ \\
\hline Rehabilitation department & {$[17,32,56,65,82,110,119,134,138]$} \\
\hline Facility for diagnostic tests & {$[5,6,31,40,41,42,66,78,92,99,130,131,137]$} \\
\hline Oncology department & {$[15,28,45,85,86,100,101,102,124]$} \\
\hline Operating room scheduling & {$[22,79,88,114,129]$} \\
\hline
\end{tabular}

A first application of MASPHs can be found in rehabilitation departments. In these departments, patients recover, amongst others, from physical injuries or drug addictions. Treating patients usually requires multiple specialists and devices from several departments. A visit to each of these resources must be carefully planned, which is often a complicated task that involves many human actors. With manual, uncoordinated planning, the resulting schedules are often far from optimal from a patient point of view [17]. Given that rehabilitation is a long-term process, patients may need to visit the same set of resources multiple times. This implies that scheduling in rehabilitation departments should focus not only on the problem of combination appointments but also on series of appointments. Another difficulty related to scheduling in rehabilitation is that some specialists organize group sessions, which have a fixed slot in the time schedule. Rehabilitation departments can treat both inpatients (e.g., [65, 119, 138]) and outpatients (e.g., $[17,82])$, although in both cases, a common goal is to finish the care pathway as soon as medically possible. When only looking at the papers focusing on an outpatient department, researchers also try to schedule as many treatments as possible on one day such that patients need to visit the hospital as little as possible (e.g., [17, 82]). An example of such scheduling problems can be found in Braaksma et al. [17], who study a rehabilitation center and apply an integer linear programming approach to implement combination appointments. Doing so increases patient satisfaction because patients can now be scheduled such that they have fewer 
visits to the hospital and see more care providers in one visit. At the same time, the simulation results show that implementing the new scheduling technique will significantly increase the number of patients with an access time within two weeks compared to their baseline scenario.

The second application of MASPHs occurs when patients need to be scheduled for diagnostic tests. These tests often do not take a long time, so it is possible for patients to undergo multiple tests in a single day. Doing so allows doctors to diagnose patients faster. As such, the majority of this subset of manuscripts aims to minimize the completion time of all steps in the care chain. Thanks to the characteristics of diagnostic tests, these problems can also be conveniently modelled as an open shop (e.g., [131]), a flow shop (e.g., [31]) or a hybrid shop (e.g., [6]), depending on the precedence constraints. A hybrid shop is an open shop with partial precedence constraints [6]. The tests are usually followed by a consultation (e.g., [130, 131]) such that the doctor can decide on the course of treatment (either new tests or some treatment). It is important to note that not all diagnostic facilities employ appointments to schedule patients on tests. Some also rely on queuing and thus only need to determine when to admit patients to the hospital (e.g., [54, 55, 113]). Such approaches are not considered in this paper because their scope violates the inclusion restriction discussed in Section 4. An example of scheduling on diagnostic tests can be found in Vermeulen et al. [131], who develop a new multi-agent Paretoimprovement appointment exchanging algorithm. This algorithm starts from a schedule (firstcome-first-served or first-come-random-served) on several diagnostic resources (among others Doppler, echo and CT-scan) and interchanges the existing appointments that have been scheduled using single-resource algorithms by using different agents (patient agents, resource agents, staff agents) to improve the existing schedules. The algorithm is applied in a real-life setting, and it is shown that the solution value of the new schedules (which is driven mainly by the equality of the workload distribution) lies very close to the global optimum.

A third application of MASPHs can be found in the oncology department. Although the main research focus in these departments is on the scheduling of patients on the chemotherapy chairs or linear accelerators (used for radiotherapy), some research has also been dedicated to the scheduling process for the entire care pathway, including consultations with oncologists and/or pre-treatment stages. This research is motivated by the idea that delaying treatment could have adverse effects on the patient $[46,90,109]$. Therefore, minimizing the time needed to complete the path, including the pre-treatment stages, can be very important (e.g., [34, 35, 112, 117]). Authors may also choose to expand their focus from the chemotherapy or radiotherapy scheduling to the consultation of the patients with their coordinating physician. An example of the latter can be found in Liang et al. [86]. In this paper, the authors try to improve the performance of a chemotherapy pathway by simultaneously scheduling the consultation with an oncologist and the chemotherapy treatment. By using a mathematical programming approach, the authors reduce the patient waiting times and achieve a more balanced resource utilization. The interested reader is also referred to Vieira et al. [132] for a recent literature review of 
radiotherapy scheduling. Note as well that radiotherapy and chemotherapy scheduling is a field of study in which appointment series play an important role, as patients usually require more than one visit to the oncology department in order to treat or to limit the growth of the tumor. As such, scheduling patients for their entire treatment pathway may also be important in these problems. Noticeable research efforts in this field of study can be found in $[26,33,34,37,53$, $59,73,103,104,112,115,117,120,126]$.

The number of departments in which MASPHs have been studied is, as shown by the enumeration above, rather limited. However, it should be noted that this result can be explained by the fact that not all hospital departments rely on scheduling. For example, emergency departments let patients queue with priorities for resources and do usually not focus on scheduling. One noticeable exception to this rule can be found in Luscombe and Kozan [89]. In this work, the authors assume that, once triaged, each incoming emergency patient can be assigned a treatment path that needs to be completed before a further treatment decision is taken. The different steps in the treatment path are then dynamically scheduled (i.e. appointments can still change with new arriving patients), taking into account the urgency of the patient. Their algorithm is designed to quickly update the existing schedule each time a new patient is admitted to the emergency department. Likewise, scheduling in operating rooms, which is a well-researched field of study, uses scheduling as an admission planning technique, with patients being transferred from pre-operative stages to the anesthesia unit and the operating room as soon as the next resource in the chain is available. An exception to this rule is described by Vasilakis et al. [129], who focus on the consultation that precedes a surgery. By using a shared waiting list for all surgeons and all priority classes (referred to as a pooled list), the authors can significantly reduce both the access time and the time between the appointment and the surgery.

\subsection{Patient mix}

Once the hospital department has been defined, the researcher knows the context of the problem and what attributes can be changed. This allows a shift in the focus to the patients who need to be diagnosed or treated. In this review, three types of patients are identified: outpatients, inpatients and emergency patients. Table 4 provides a classification of the selected papers along this dimension.

First, outpatient clinics treat patients who do not spend the night in the hospital [139]. This mainly implies that the patient goes home after all necessary services have been provided to the patient. The term 'outpatient department' can either refer to a separate clinic (which is organized around a specialty or a certain medical condition) or a subdivision of a general hospital in which consultations are organized during specific timeframes [139]. The main challenges on the operational decision level in outpatient procedure planning are the uncertain 
service times and patient no-shows [11, 12, 125]. The level of no-shows is explained by the fact that outpatients might have forgotten about the appointment or might encounter transportation problems. To reduce the impact of the aforementioned problems, Chern et al. [31] try to use a heuristic ('health examination scheduling algorithm') to create a one-stop shop in a hospital unit that organizes a multitude of diagnostic tests. Comparing the results of the new heuristic with a real-life manually constructed schedule shows that the algorithm is capable of doubling the number of scheduled patients, resulting in higher revenue for the hospital.

Second, inpatient care treats patients who do spend the night in the hospital. In this situation, a patient also requires a bed; thus, when planning the patients over all resources, an additional constraint on the total number of beds in the system is required (e.g., [36]). Given that the length-of-stay (the total number of days and nights that a patient occupies a bed) in inpatient care is an important factor for hospital profitability, most of the work in inpatient care focuses on minimizing the time to complete the total path. As patients are already in the hospital, taking patient preferences into account regarding the timing of their appointments does not make sense. In this subset of papers, doctors are usually not included, with papers focusing mostly on scheduling the treatment or diagnostic resources. This is also the case for Conforti et al. [36], who model a week-long hospital scheduling problem. In this problem, the authors use a mixed integer linear program to see which patients on the waiting list can be admitted to the hospital. The program only admits patients if they can be discharged within one week. Applying the model to data from a rheumatology division shows that the number of admitted patients can be increased, resulting in higher revenue for the unit.

Third, emergency patients are usually not the subject of multi-appointment scheduling because their arrival is unforeseen and the patient needs to receive care immediately. In our group of included papers, there are two exceptions: the work of Luscombe and Kozan [89] (which was already discussed in Section 5.1) and the work of Azadeh et al. [5]. In this paper, the authors focus on a diagnostic laboratory that is tied to the emergency department. Patients are scheduled as soon as it is determined which tests the patient needs. The laboratory is organized as an open shop to minimize the time required to complete all the tests. Their genetic algorithm was applied to data from a real emergency department, and the results showed that the new system significantly reduced the time to complete all tests compared to the system that was implemented in the actual department.

Additionally, emergency patients are important to consider when scheduling outpatients or inpatients because sufficient capacity must remain available to serve the incoming emergency patients. If there is insufficient remaining capacity on the resources, the scheduled appointments need to be pushed back. This can result in overtime and delayed appointments. The latter is not desirable in an MASPH because patients may be expected for other resources. An example of this problem is given by Vasilakis et al. [129], who note that patients belonging to the 
emergency pathway must be scheduled to the next surgical slot. One way to account for these emergency patients would be to reserve capacity. However, none of the selected papers uses this strategy. Instead, authors assume that emergency patients are known beforehand (e.g. [28, 48, $100,102])$ or that they will simply be booked in the remaining open slots when they arrive (e.g. $[28,129])$.

Table 4: Classification based on patient mix.

\begin{tabular}{|c|c|c|}
\hline \multicolumn{2}{|c|}{ Type of patients to be seen in the hospital } & \multirow{2}{*}{$\begin{array}{l}\text { References } \\
{[22,36,40,41,48,52,56,63,64,65,74,} \\
76,88,92,97,98,110,111,114,138]\end{array}$} \\
\hline \multirow{5}{*}{ Patient mix } & Inpatient & \\
\hline & Outpatient & $\begin{array}{l}{[4,6,15,17,28,31,45,66,82,86,99,100,} \\
102,124,129,130,137]\end{array}$ \\
\hline & Inpatients and outpatients & {$[39,78,79,85,119]$} \\
\hline & Emergency patients & {$[5,89]$} \\
\hline & $\begin{array}{l}\text { Patient mix is not explicitly } \\
\text { mentioned }\end{array}$ & $\begin{array}{l}{[32,42,43,44,61,75,77,96,101,105,} \\
131,134]\end{array}$ \\
\hline $\begin{array}{l}\text { Emergency } \\
\text { patients }\end{array}$ & $\begin{array}{l}\text { Emergency patients or walk-ins } \\
\text { need to be considered but are not } \\
\text { the main patient group }\end{array}$ & {$[28,48,78,89,100,102,129]$} \\
\hline
\end{tabular}

\subsection{Resources}

To complete the scope of the problem, the researcher needs to define the set of hospital resources that are modelled as realistically as possible in the problem. This set needs to be well defined, well considered and aligned with the situation in practice because the decisions made in this stage of the research strongly influence the complexity of the problem [128]. When practical healthcare issues drive researchers to include, e.g., consultations with doctors (see Table 5 for an overview), then those researchers are bound by the availability of the doctor, which can greatly decrease the search space for a solution compared to that of a situation in which all resources are continuously available. To reduce the complexity of a multiappointment problem, authors can make simplifying assumptions such as that all tests take the same amount of time for all patients (e.g., [6]). However, unless the work has a theoretical nature, those simplifying assumptions may never violate the real-life situation upon which the problem is modelled. Resources included in the problem can be used for treatment purposes (e.g., rehabilitation, radiotherapy or chemotherapy) or for diagnostic purposes, as shown in Table 5 . 
Table 5: Classification based on the required resources.

\begin{tabular}{lll}
\hline \multicolumn{2}{l}{ Resource constraints } & References \\
\hline \multirow{2}{*}{ Consultation } & $\begin{array}{l}\text { Patients need a consultation with a } \\
\text { doctor }\end{array}$ & $\begin{array}{l}{[4,17,28,31,44,45,48,56,66,74,76,79,} \\
82,85,86,88,100,102,110,124,129,130, \\
131]\end{array}$ \\
\hline & $\begin{array}{l}\text { Resources are used for treatment } \\
\text { purposes }\end{array}$ & $\begin{array}{l}{[15,22,32,36,56,65,79,82,86,88,101,} \\
110,111,129,138]\end{array}$ \\
\cline { 2 - 3 } Resource & Resources are used for diagnostic & {$[5,31,39,40,41,42,61,66,76,78,85,92$,} \\
purpose & purposes & $99,100,130,131,137]$
\end{tabular}

\section{Choosing what to optimize}

When arriving at this stage of the research process, most of the constraints and the limitations of the chosen setting are known to the researcher. Therefore, the time has come to address the question of what needs to be optimized (see also Table 6) and how performance in the hospital is defined (see Table 7). In integrated healthcare, a significant emphasis has been put on creating patient-centered operations in hospitals to increase patient satisfaction. After all, being helped immediately in a hospital is a large determinant of patient satisfaction [95]. Table 6 shows, however, that not all research efforts in the MASPH literature are dedicated to minimizing the completion time of the path or maximizing the patient satisfaction. Indeed, because hospitals need to become more cost-efficient and face budget cuts [1], profit maximization is becoming a hot topic. Hence, the goal of MASPHs can be broadly classified in two categories. On the one hand, hospitals can choose to follow the goals of the integrated healthcare literature and maximize patient satisfaction, minimize the access time or minimize the completion time of all tasks. On the other hand, some hospitals prefer to maximize profit by maximizing the number of patients scheduled, maximizing the contribution margin or minimizing the idle time of resources. Both objective function types can be valid, depending on the context, and in both types, MASPHs have proven to be efficient and effective. The option of choosing between the goals of integrated healthcare and profit also explains the existence of papers with multiple goals, either by assigning weights to each part of the objective function or by having multiple optimization stages. In this way, researchers have the opportunity to let hospitals decide which objective function type is desired. An example of the latter can be found in Kortbeek et al. [82], who focus on a one-stop shop that serves children with neuromuscular diseases. In this case, the patients need to undergo a series of follow-up tests and consultations each year, and the facility wants to organize the care for these patients in such a way that each patient only needs to come to the hospital unit one time, thereby relieving stress for both parents and children. They do so by using an ILP approach with multiple goals in the objective function, 
for which both profitability (maximize the number of patients scheduled and maximize the total treatment time per resource) and patient satisfaction (minimize the idle time for patients) are considered. The hospital can determine the weights that are allocated to each part of the objective function.

Table 6: Classification based on objective function: Single objective versus multiple objectives

\begin{tabular}{ll}
\hline Type of objective function & References \\
\hline & {$[5,6,36,39,40,41,42,43,44,48,52$,} \\
Single objective & $63,64,65,66,76,78,79,96,97,98,99$, \\
& $105,114,119,124,129,130,131,134$, \\
& $137]$ \\
\hline Multiple objectives, with weights & {$[4,15,17,22,32,56,74,82,85,88,89$,} \\
\hline Multiple objectives, with different stages & $92,101,111]$ \\
\hline Does not discuss an objective function, only reports on the & {$[28,31,61,75,77,86,100,102,138]$} \\
implementation of a new scheduling rule & {$[45,110]$} \\
\hline
\end{tabular}

Table 7: Classification based on objective function: What is optimized?

\section{Goals in the objective function}

Minimize access time (or percentage of patients who cannot be seen before a certain deadline)

\section{References}

$[17,28,32,88,100,101,102,111]$

Minimize the idle time of resources

$[15,17,31,74,82,85,89,92]$

Maximize satisfaction

$[4,39,44,92,97,98]$

Minimize the time to complete all tasks (or minimize the waiting time between two consecutive steps)

$[5,6,17,31,32,40,41,42,43,48,63$, $64,65,66,75,76,78,85,88,89,99$, $100,101,102,111,114,124,129,131$, $137,138]$

Maximize the number of patients scheduled (with and $[22,36,39,74,82,99,119,134]$ without patient priority)

Other objective function $[4,17,22,52,56,61,77,79,85,86,88$, $96,101,105,130]$

No objective function $[45,110]$ 


\section{Choosing how to optimize}

In the previous decision stages, both the objective function and all constraints of the problem are defined step by step meaning, the model is now complete. Researchers should now choose which methodology is appropriate for achieving the desired goal. It is important to remember that researchers need to communicate with the hospital about these choices in order to maximize the relevance for practice and the chances of implementation. In doing so, researchers should not only choose a scheduling technique but also a scheduling strategy. For this paper, this refers to the distinction between online and offline scheduling. Indeed, upon receiving a request for service, schedulers have two options regarding their response time to the request. On the one hand, they can respond immediately with a date and time for the requested appointments. This implies that scheduling becomes a sequential process in which patients are given appointments in the order of the arrival time of their request. On the other hand, schedulers might also want to wait and collect requests for appointments in a waiting list, after which an algorithm is applied to select patients from this list. Following the appointment literature [135], we refer to the former scheduling strategy as online scheduling and the latter as offline scheduling. Table 8 classifies the selected papers along this dimension. Choosing the scheduling strategy is not a lightweight task as both scheduling strategies imply a different model of operations for the hospital. When using waiting lists, schedulers should, however, note that patients cannot remain on the list for a long period of time because patient satisfaction will decrease as the urgency level of the patient increases [21]. Additionally, in an outpatient situation, there is the additional risk that patients will visit the emergency department to be treated sooner [94] as the emergency department generally cannot refuse these patients.

Table 8: Classification based on scheduling strategy

\begin{tabular}{ll}
\hline Scheduling type & References \\
\hline \multirow{2}{*}{ Online scheduling } & {$[6,17,28,42,44,45,63,77,78,79,82,89,92,97$,} \\
& $98,99,124,130,131]$ \\
\hline & {$[5,15,22,31,32,36,39,40,41,48,52,56,61,64$,} \\
Offline scheduling & $65,66,74,75,76,85,86,88,96,99,100,101$, \\
& $102,105,110,111,114,119,129,131,134,137$, \\
& $138]$ \\
\hline
\end{tabular}

Scheduling strategy not mentioned

$[4,43]$

When choosing a scheduling methodology, different options are available. Some of these options provide optimal solutions (exact methods), and others only provide near-optimal solutions (heuristics). The struggle here is mainly to find an optimal balance in the trade-off between the quality of the solution and the computation time [15]. In the case of an online scheduling strategy, the method needs to be applied each time a new request for an appointment is received. Therefore, the computation times should be short, limiting the efforts to solve reallife instances to mostly (meta)heuristics. However, such methods only search a small part of the 
search space, which rarely results in the best solution. In contrast, hospitals want to provide a treatment plan that increases the patient satisfaction level and maintains the throughput at acceptable levels. In offline scheduling, the number of patients for which an appointment needs to be scheduled is higher, so the complexity of the problem increases rapidly. As in the online cases, an optimal solution often remains something to which we can only aspire. The consequence of this reasoning can be found in Table 9, which shows that the number of exact scheduling methods is fairly limited compared to the number of papers that search for nearoptimal solutions. The set of near-optimal solution methods is roughly equally dominated by popular metaheuristics (such as genetic algorithms and tabu search) and multi-agent methods. Metaheuristics search the neighborhood of a solution (or set of solutions) to create better solutions. Multi-agent methods assign an agent to each stakeholder in the scheduling process who has known requirements and interests. The goal is to create a schedule that is consistent with the constraints and preferences of all agents [91]. The creation of this schedule can be the result of different techniques, such as the application of constructive heuristics. A common approach in this methodology is to simulate a combinatorial auction in which the auctioned items are the time slots provided by the resource agents. The willingness-to-pay for each item or combination of items is then influenced by the optimization goal. For a complete review of papers that use multi-agent theory in healthcare, we refer to Isern et al. [72], Isern and Moreno [71] and Iqbal et al. [70].

The attentive reader also notices that methods such as queuing theory and Markov Decision Processes (MDP) are not present in Table 9. This can be explained by noting that both methodologies rely on patient flow rather than scheduling techniques. In queuing theory, for example, patients go directly to the next resource and start queuing. A common goal in these problems is to compute the average waiting time for a patient to go through the system (see [7, 139, 140] for examples). An MDP is essentially a sequential decision model. It describes a system in a state $S_{t}$, and due to an action $x_{t}$, the system transforms into another state $S_{t+1}$. This happens according to a transition function, describing the probability that an action $\mathrm{x}_{\mathrm{t}}$ in state $\mathrm{S}_{\mathrm{t}}$ will result in state $S_{t+1}[108]$. Garg et al. [51], for example, model the patient transition process through a healthcare system, assuming that the patient moves from one stage to another without requiring an appointment on the next resource. A similar approach can be found in the work of Hulshof et al. [69], in which patients either flow to the next resource and queue or leave the system. We refer to Schaefer et al. [118] for other examples. However, using the definition of the MDP problem, one can argue that in patient scheduling, each new appointment can be defined as an action $\mathrm{x}_{\mathrm{t}}$, resulting in a new state that can be described by a vector of already booked patients. This has already been applied to single-resource scheduling (see Gocgun et al. [54] for an example in computed tomography). Nonetheless, no papers have been found that use an MDP to schedule patients on multiple resources. One explanation for this research gap can be sought in the computational complexity of methods to solve an MDP [108]. 
Table 9: Classification based on methodology

\begin{tabular}{lll}
\hline Methodology & & References \\
& Metaheuristics & {$[5,6,22,32,48,65,74,89,96,100,101$,} \\
& \multirow{3}{*}{ Heuristics } & $102,105,111,134,138]$ \\
\cline { 2 - 3 } & Other heuristics & {$[4,31,39,44,56,66,76,79,89,99,110]$} \\
\cline { 2 - 3 } & Scheduling rule (e.g., FCFS, First- & {$[45,101,124,129,131,137]$} \\
& come-random-serve) & {$[40,41,42,43,63,75,78,97,98,130]$} \\
\cline { 2 - 3 } & Multi-agent theory (by auction) & {$[15,61,64,77,92]$} \\
\cline { 2 - 3 } $\begin{array}{l}\text { Exact } \\
\text { algorithms }\end{array}$ & Multi-agent theory (by other & {$[17,28,36,39,52,82,85,86,88,99,114$,} \\
\hline
\end{tabular}

Researchers should be very conscious about the implications of the chosen methodology because each methodology is directly correlated with the level of centralized scheduling in the hospital. This especially holds true if the hospital expects to implement the method developed by the researcher.

\section{Applying and validating the model}

The final steps for researchers consist of validating the model to check if the model performs as expected, using either fictional benchmark problems or real data from a collaboration with a hospital. In the case of promising results, the model is hopefully also applied in real life, effectively resulting in better care for patients. However, there seems to be a discrepancy between the number of papers that validate the results using data and the number of papers that also report on the implementation of their model. Indeed, although a significant fraction of the discussed literature validates the model using either fictional or real data, as shown in Table 10, only a fraction of the discussed literature reports on the implementation of the scheduling algorithm in practice. Obviously, it should be mentioned that papers using real data from hospitals can also implement the proposed scheduling strategy after the paper has been published. For example, Griffiths et al. [57] reports that the algorithm developed in Griffiths et al. [56] has been implemented and is currently used to schedule physiotherapy patients. The fact that few papers report on the results in practice also has some implications for the MASPH concept in general. Because very few results are generally available to the research community, it becomes more difficult to prove that multi-appointment scheduling is effective in hospitals. Therefore, it may become more difficult to convince hospitals to implement newly developed methods. The studies that were implemented in real life do not always report on the results of the implementation because the implementation process is not yet complete (e.g., [86]) or no data are available about the performance prior to the implementation (e.g., [82]). A preliminary sign that integrated scheduling can yield better results in practice is found in Dobish [45], who attempts to schedule chemotherapy sessions the day after patients have an appointment with the oncologist. This resulted in a balanced workload for the pharmacy that has to deliver the chemotherapy and higher patient satisfaction. More recently, Chern et al. [31] showed that the 
application of multi-appointment scheduling in an examination center in Taiwan doubled the revenue of the center.

When investigating scientific work that uses real data, similar results can be found. The scheduling algorithm of Conforti et al. [36], for example, admits more patients to an inpatient hospital. When scheduling appointments for a consultation and a surgery, Vasilakis et al. [129] reduce the length of the waiting list for a clinic appointment by $30 \%$ by using a shared waiting list for all surgeons and all priority classes (referred to as a pooled list). To continue these examples, the genetic algorithm in Petrovic et al. [100] significantly reduces the wait time for radiology treatment for all patient types, and the mixed integer program developed by Gartner and Kolisch [52] results in an up to 6\% higher contribution margin for a surgical care pathway. In fact, in all departments mentioned in Section 5.1, positive results can be found when a centralized scheduling approach is applied to real data. However, as long as these theoretical results are not proven in practice, they need to be interpreted with care. Therefore, it seems that, similar to integrated healthcare $[49,87]$, proving the effectiveness of multi-appointment hospital scheduling remains difficult. Few studies monitor the performance before implementation and report on the performance improvements after implementation. When proposing a new methodology, it always remains questionable for other researchers and practitioners in the field whether the method results in better performance.

Table 10: Classification based on the type of data used.

\begin{tabular}{ll}
\hline Data included in the scientific work & References \\
\hline Tested with fictional data & {$[5,15,22,42,43,63,64,75,77,78,89,92,97,98$,} \\
& $114,119,130,138]$ \\
\hline \multirow{2}{*}{ Tested with real data, but not applied in practice } & {$[4,5,6,17,28,31,32,36,39,40,41,44,48,52$,} \\
& $124,66,74,79,85,88,99,100,101,102,105,111$, \\
\hline Tested in practice, ongoing or not permanently & {$[65,82,86]$} \\
implemented & {$[45]$} \\
\hline Tested in practice, permanently implemented & {$[61,76,96,110,131]$} \\
\hline Paper does not use data & \\
\hline
\end{tabular}

\section{Conclusion}

This paper provides a review of multi-appointment scheduling problems in hospitals. In these problems, patients require appointments for multiple resource types. This field of literature has only gained research interest in recent years. One explanation for this phenomenon can be found in the fact that hospital resources are often managed individually without looking at the larger picture. This is especially true if the resources are located in multiple departments. A second explanation can be found in the popularity of the patient flow literature. In such problems, patients do not need to be scheduled, and they queue for the next resource or leave the system when their request for service at a given resource has been fulfilled. The main objective of this 
work is to help researchers in the field of multi-appointment scheduling in hospitals by enumerating for each step of the research the available choices in the current literature. These steps are illustrated with examples from the literature so researchers can easily find the research efforts that are tailored to their needs. When reviewing these options, researchers should not forget to align their choices over all decision stages. We have shown that MASPHs are currently only found in a limited number of hospital departments that rely fully on scheduling. The popular methodologies for solving an MASPH are metaheuristics and multi-agent methods. Exact methods are less popular due to the complexity of the problem. We have also established that few manuscripts report on the implementation of their methods in practice. As a result, practitioners have little evidence or guidance available. To further expand the field of multiappointment scheduling in hospitals, such practical results need to be included in future research efforts.

\section{Acknowledgements}

This work was supported by the Research Foundation - Flanders (grant provided to Joren Marynissen - aspirant).

\section{References}

[1] Ahmadi-Javid, A., Jalali, Z. and Klassen, K. J., "Outpatient appointment systems in healthcare: A review of optimization studies," European Journal of Operational Research, vol. 258, no. 1, pp. 3-34, 2017.

[2] Anthony, R. N., Planning and control systems: A framework for analysis, PhD thesis. Boston: Harvard University, 1965.

[3] Armitage, G. D., Suter, E., Oelke, N. D. and Adair, C. E., "Health systems integration: State of the evidence," International Journal of Integrated Care, vol. 9, no. 2, 2009.

[4] Aslani, N. and Zhang, J., "Integration of simulation and DEA to determine the most efficient patient appointment scheduling model for a specific healthcare setting," Journal of Industrial Engineering and Management, vol. 7, no. 4, pp. 785-815, 2014.

[5] Azadeh, A., Farahani, M. H., Torabzadeh, S. and Baghersad, M., "Scheduling prioritized patients in emergency department laboratories," Computer Methods and Programs in Biomedicine, vol. 117, no. 2, pp. 61-70, 2014.

[6] Azadeh, A., Baghersad, M., Farahani, M. H. and Zarrin, M., "Semi-online patient scheduling in pathology laboratories," Artificial Intelligence in Medicine, vol. 64, no. 3, pp. 217-226, 2015.

[7] Baesler, F. F. and Sepúlveda, J. A., "Multi-objective simulation optimization for a cancer treatment center," in Proceedings of the 2001 Winter Simulation Conference, Arlington, 2001, pp. 1405-1411.

[8] Bailey, N. T. J., "A study of queues and appointment systems in hospital outpatient departments with special reference to waiting times," Journal of the Royal Statistical Society, vol. 14, no. 2, pp. 185-199, 1952. 
[9] Barz, C. and Rajaram, K., "Elective patient admission and scheduling under multiple resource constraints," Production and Operations Management, vol. 24, no. 12, pp. 1907-1930, 2015.

[10] Berenson, R. A., Bodenheimer, T. and Pham, H. H., "Specialty-service lines: Salvos in the new medical arms race," Health Affairs, vol. 25, no. 5, pp. w337-w343, 2006.

[11] Berg, B. P. and Denton, B. T., "Appointment planning and scheduling in outpatient procedure centers," in Handbook of Healthcare System Scheduling, vol. 168, Hall, R., Ed. Boston: Springer US, 2012, pp. 131-154.

[12] Berg, B. P., Denton, B. T., Erdogan, S. A., Rohleder, T. R. and Huschka, T., "Optimal booking and scheduling in outpatient procedure centers," Computers and Operations Research, vol. 50, pp. 24-37, 2014.

[13] Van Den Bergh, J., Belien, J., De Bruecker, P., Demeulemeester, E. and De Boeck, L., "Personnel scheduling: A literature review," European Journal of Operational Research, vol. 226, no. 3, pp. 367-385, 2013.

[14] Bikker, I. A., Kortbeek, N., van Os, R. M. and Boucherie, R. J., "Reducing access times for radiation treatment by aligning the doctor's schemes," Operations Research for Health Care, vol. 7, pp. 111-121, 2015.

[15] Billiau, G., Chang, C. F., Ghose, A. and Miller, A. A., "Using distributed agents for patient scheduling," in Principles and Practice of Multi-Agent Systems, 13th International Conference, Kolkata, 2010, pp. 551-560.

[16] Bowers, J., Lyons, B., Mould, G. and Symonds, T., "Modelling outpatient capacity for a diagnosis and treatment centre," Health Care Management Science, vol. 8, no. 3, pp. 205-211, 2005.

[17] Braaksma, A., Kortbeek, N., Post, G. F. and Nollet, F., "Integral multidisciplinary rehabilitation treatment planning," Operations Research for Health Care, vol. 3, no. 3, pp. 145-159, 2014.

[18] Bredenhoff, E., van Lent, W. A. M. and van Harten, W. H., "Exploring types of focused factories in hospital care: A multiple case study," BMC Health Services Research, vol. $10,2010$.

[19] Brucker, P., Scheduling algorithms, 5th ed. Berlin: Springer, 2007.

[20] De Bruin, A. M., Koole, G. M. and Visser, M. C., "Bottleneck analysis of emergency cardiac in-patient flow in a university setting: An application of queueing theory," Clinical and Investigative Medicine, vol. 28, no. 6, pp. 316-317, 2005.

[21] Buhaug, H., "Long waiting lists in hospitals: Operational research needs to be used more often and may provide answers," British Medical Journal, vol. 324, no. 7332, pp. 252253, 2002.

[22] Burdett, R. L. and Kozan, E., "An integrated approach for scheduling health care activities in a hospital," European Journal of Operational Research, vol. 264, no. 2, pp. 756-773, 2018.

[23] Burdett, R. L. and Kozan, E., "A multi-criteria approach for hospital capacity analysis," European Journal of Operational Research, vol. 255, no. 2, pp. 505-521, 2016. 
[24] Burdett, R. L., Kozan, E., Sinnott, M., Cook, D. and Tian, Y. C., "A mixed integer linear programing approach to perform hospital capacity assessments," Expert Systems with Applications, vol. 77, pp. 170-188, 2017.

[25] Burke, E. K., De Causmaecker, P., Vanden Berghe, G. and Van Landeghem, H., "The state of the art of nurse rostering," Journal of Scheduling, vol. 7, no. 6, pp. 441-449, 2004.

[26] Burke, E. K., Leite-Rocha, P. and Petrovic, S., "An integer linear programming model for the radiotherapy treatment scheduling problem," Unpublished results.

[27] Cardoen, B., Demeulemeester, E. and Beliën, J., "Operating room planning and scheduling: A literature review," European Journal of Operational Research, vol. 201, no. 3, pp. 921-932, 2010.

[28] Castro, E. and Petrovic, S., "Combined mathematical programming and heuristics for a radiotherapy pre-treatment scheduling problem," Journal of Scheduling, vol. 15, no. 3, pp. 333-346, 2012.

[29] De Causmaecker, P. and Vanden Berghe, G., "A categorisation of nurse rostering problems,” Journal of Scheduling, vol. 14, no. 1, pp. 3-16, 2011.

[30] Cayirli, T. and Veral, E., "Outpatient scheduling in health care: A review of literature," Production and Operations Management, vol. 12, no. 4, pp. 519-549, 2003.

[31] Chern, C.-C., Chien, P.-S. and Chen, S.-Y., "A heuristic algorithm for the hospital health examination scheduling problem," European Journal of Operational Research, vol. 186, no. 3, pp. 1137-1157, 2008.

[32] Chien, C.-F., Tseng, F.-P. and Chen, C.-H., "An evolutionary approach to rehabilitation patient scheduling: A case study," European Journal of Operational Research, vol. 189, no. 3, pp. 1234-1253, 2008.

[33] Condotta, A. and Shakhlevich, N. V., "Scheduling patient appointments via multilevel template: A case study in chemotherapy," Operations Research for Health Care, vol. 3, no. 3, pp. 129-144, 2014.

[34] Conforti, D., Guerriero, F. and Guido, R., "Optimization models for radiotherapy patient scheduling," 4OR, vol. 6, no. 3, pp. 263-278, 2008.

[35] Conforti, D., Guerriero, F. and Guido, R., "Non-block scheduling with priority for radiotherapy treatments," European Journal of Operational Research, vol. 201, no. 1, pp. 289-296, 2010.

[36] Conforti, D., Guerriero, F., Guido, R., Cerinic, M. M. and Conforti, M. L., "An optimal decision making model for supporting week hospital management.," Health Care Management Science, vol. 14, no. 1, pp. 74-88, 2011.

[37] Conforti, D., Guerriero, F., Guido, R. and Veltri, M., "An optimal decision-making approach for the management of radiotherapy patients," OR Spectrum, vol. 33, no. 1, pp. 123-148, 2011.

[38] Cook, D., Thompson, J. E., Habermann, E. B., Visscher, S. L., Dearani, J. A., Roger, V. L. and Borah, B. J., "From 'solution shop' model to 'focused factory' in hospital surgery: Increasing care value and predictability," Health Affairs, vol. 33, no. 5, pp. 746$755,2014$. 
[39] Cordier, J.-P. and Riane, F., "Towards a centralised appointments system to optimise the length of patient stay," Decision Support Systems, vol. 55, no. 2, pp. 629-639, 2013.

[40] Decker, K. and Li, J., "Coordinated hospital patient scheduling," in International Conference on Multi Agent Systems, Paris, 1998, pp. 104-111.

[41] Decker, K. and Li, J., "Coordinating mutually exclusive resources using GPGP," Autonomous Agents and Multi-agent Systems, vol. 3, no. 2, pp. 133-157, 2000.

[42] Deshpande, U., Gupta, A. and Basu, A., "A distributed hospital resource scheduling system using a multi-agent framework," IETE Technical Review, vol. 18, no. 4, pp. 263$275,2001$.

[43] Deshpande, U., Gupta, A. and Basu, A., "Coordinated problem solving through resource sharing in a distributed environment," IEEE Transactions on Systems, Man, and Cybernetics, Part B: Cybernetics, vol. 34, no. 2, pp. 1299-1304, 2004.

[44] Dharmadhikari, N. and Zhang, J., "Simulation optimization of blocking appointment scheduling policies for multi-clinic appointments in centralized scheduling systems," International Journal of Engineering and Innovative Technology, vol. 2, no. 11, pp. 196-201, 2013.

[45] Dobish, R., "Next-day chemotherapy scheduling: A multidisciplinary approach to solving workload issues in a tertiary oncology center," Journal of Oncology Pharmacy Practice, vol. 9, no. 1, pp. 37-42, 2003.

[46] Donahue, R., Russell, D., de Riese, C., Smith, C., de Riese, W. T. W. and Medway, A., "Patients willing to wait: Arrival time, wait time and patient satisfaction in an ambulatory urology clinic," Urology Practice, vol. 4, no. 1, pp. 1-6, 2017.

[47] Drupsteen, J., van der Vaart, T. and van Donk, D. P., "Integrative practices in hospitals and their impact on patient flow," International Journal of Operations and Production Management, vol. 33, no. 7, pp. 912-933, 2013.

[48] Du, G., Jiang, Z., Yao, Y. and Diao, X., "Clinical pathways scheduling using hybrid genetic algorithm," Journal of Medical Systems, vol. 37, no. 3, 2013.

[49] Foglino, S., Bravi, F., Carretta, E., Fantini, M. P., Dobrow, M. J. and Brown, A. D., "The relationship between integrated care and cancer patient experience: A scoping review of the evidence," Health Policy, vol. 120, no. 1, pp. 55-63, 2016.

[50] Froehle, C. M. and Magazine, M. J., "Improving scheduling and flow in complex outpatient clinics," in Handbook of Healthcare Operations Management, vol. 184, Denton, B. T., Ed. New York: Springer, 2013, pp. 229-250.

[51] Garg, L., McClean, S., Meenan, B. J. and Millard, P., "A non-homogeneous discrete time Markov model for admission scheduling and resource planning in a cost or capacity constrained healthcare system," Health Care Management Science, vol. 13, no. 2, pp. 155-169, 2010.

[52] Gartner, D. and Kolisch, R., "Scheduling the hospital-wide flow of elective patients," European Journal of Operational Research, vol. 233, no. 3, pp. 689-699, 2014.

[53] Gocgun, Y., "Simulation-based approximate policy iteration for dynamic patient scheduling for radiation therapy," Health Care Management Science, in press. 
[54] Gocgun, Y., Bresnahan, B. W., Ghate, A. and Gunn, M. L., "A Markov decision process approach to multi-category patient scheduling in a diagnostic facility," Artificial Intelligence in Medicine, vol. 53, no. 2, pp. 73-81, 2011.

[55] Godin, P. and Wang, C., "Agent-based outpatient scheduling for diagnostic services," in IEEE International Conference on Systems, Man and Cybernetics, Istanbul, 2010, pp. $1851-1856$.

[56] Griffiths, J. D., Williams, J. E. and Wood, R. M., "Scheduling physiotherapy treatment in an inpatient setting," Operations Research for Health Care, vol. 1, no. 4, pp. 65-72, 2012.

[57] Griffiths, J. D., Williams, J. E. and Wood, R. M., "Modelling activities at a neurological rehabilitation unit," European Journal of Operational Research, vol. 226, no. 2, pp. 301-312, 2013.

[58] Gupta, D. and Denton, B. T., "Appointment scheduling in health care: Challenges and opportunities," IIE Transactions, vol. 40, no. 9, pp. 800-819, 2008.

[59] Hahn-Goldberg, S., Carter, M. W., Beck, J. C., Trudeau, M., Sousa, P. and Beattie, K., "Dynamic optimization of chemotherapy outpatient scheduling with uncertainty," Health Care Management Science, vol. 17, no. 4, pp. 379-392, 2014.

[60] Hall, R., Patient flow: Reducing delay in healthcare delivery. Boston: Springer, 2013.

[61] Hannebauer, M. and Müller, S., "Distributed constraint optimization for medical appointment scheduling," in Proceedings of the Fifth International Conference on Autonomous Agents, Montreal, 2001, pp. 139-140.

[62] Hans, E. W., van Houdenhoven, M. and Hulshof, P. J. H., "A framework for healthcare planning and control," in Handbook of Healthcare System Scheduling, Hall, R., Ed. New York: Springer International Publishing, 2013, pp. 303-320.

[63] Hsieh, F.-S., "A hybrid and scalable multi-agent approach for patient scheduling based on Petri net models," Applied Intelligence, vol. 47, no. 4, pp. 1068-1086, 2017.

[64] Hsieh, F.-S. and Lin, J.-B., "Scheduling patients in hospitals based on multi-agent systems," in International Conference on Industrial, Engineering and Other Applications of Applied Intelligent Systems, Kaohsiung, 2014, pp. 32-42.

[65] Huang, Y.-C., Zheng, J.-N. and Chien, C.-F., "Decision support system for rehabilitation scheduling to enhance the service quality and the effectiveness of hospital resource management," Journal of the Chinese Institute of Industrial Engineers, vol. 29, no. 5, pp. 348-363, 2012.

[66] Huang, Y.-L., "Ancillary service impact on outpatient scheduling," International Journal of Health Care Quality Assurance, vol. 26, no. 8, pp. 746-759, 2013.

[67] Hulshof, P. J. H., Boucherie, R. J., Hans, E. W. and Hurink, J. L., "Tactical resource allocation and elective patient admission planning in care processes," Health Care Management Science, vol. 16, no. 2, pp. 152-166, 2013.

[68] Hulshof, P. J. H., Kortbeek, N., Boucherie, R. J., Hans, E. W. and Bakker, P. J. M., "Taxonomic classification of planning decisions in health care: A structured review of the state of the art in OR/MS," Health Systems, vol. 1, no. 2, pp. 129-175, 2012. 
[69] Hulshof, P. J. H., Mes, M. R. K., Boucherie, R. J. and Hans, E. W., "Patient admission planning using approximate dynamic programming," Flexible Services and Manufacturing Journal, vol. 28, no. 1-2, pp. 30-61, 2016.

[70] Iqbal, S., Altaf, W., Aslam, M., Mahmood, W. and Khan, M. U. G., "Application of intelligent agents in health-care: Review," Artificial Intelligence Review, vol. 46, no. 1, pp. 83-112, 2016.

[71] Isern, D. and Moreno, A., "A systematic literature review of agents applied in healthcare," Journal of Medical Systems, vol. 40, no. 2, 2016.

[72] Isern, D., Sánchez, D. and Moreno, A., "Agents applied in health care: A review," International Journal of Medical Informatics, vol. 79, no. 3, pp. 145-166, 2010.

[73] Jacquemin, Y., Marcon, E. and Pommier, P., "A pattern-based approach of radiotherapy scheduling," in Proceedings of the 18th World Congress of the International Federation of Automatic Control, Milan, 2011, pp. 6945-6950.

[74] Jerić, S. V. and Figueira, J. R., "Multi-objective scheduling and a resource allocation problem in hospitals," Journal of Scheduling, vol. 15, no. 5, pp. 513-535, 2012.

[75] Kanaga, E. G. M. and Valarmathi, M. L., "Synergy of multi-agent coordination technique and optimization techniques for patient scheduling," in International Conference on Information Technology and Mobile Communication, Nagpur, 2011, pp. 317-322.

[76] Kanaga, E. G. M., Valarmathi, M. L. and Murali, J. A., "Agent based patient scheduling using heuristic algorithm," International Journal on Computer Science and Engineering, vol. 2, no. 01S, pp. 69-75, 2010.

[77] Kanaga, E. G. M. and Valarmathi, M. L., "Multi-agent based patient scheduling using particle swarm optimization," in International Conference on Communication Technology and System Design, Coimbatore, 2012, pp. 386-393.

[78] Kanaga, E. G. M., Darius, P. S. H. and Valarmathi, M. L., "An efficient multi-agent patient scheduling using market based coordination mechanism," in International Conference on Intelligent Agent \& Multi-Agent Systems, Chennai, 2009.

[79] Kazemian, P., Sir, M. Y., Van Oyen, M. P., Lovely, J. K., Larson, D. W. and Pasupathy, K. S., "Coordinating clinic and surgery appointments to meet access service levels for elective surgery," Journal of Biomedical Informatics, vol. 66, pp. 105-115, 2017.

[80] Kifah, S. and Abdullah, S., "An adaptive non-linear great deluge algorithm for the patient-admission problem," Information Sciences, vol. 295, pp. 573-585, 2015.

[81] Kodner, D. L. and Spreeuwenberg, C., "Integrated care: Meaning, logic, applications, and implications - a discussion paper," International Journal of Integrated Care, vol. 2, no. $4,2002$.

[82] Kortbeek, N., van der Velde, M. F. and Litvak, N., "Organizing multidisciplinary care for children with neuromuscular diseases," Health Systems, vol. 6, no. 3, pp. 209-225, 2017.

[83] Kortbeek, N., Zonderland, M. E., Braaksma, A., Vliegen, I. M. H., Boucherie, R. J., Litvak, N. and Hans, E. W., "Designing cyclic appointment schedules for outpatient clinics with scheduled and unscheduled patient arrivals," Performance Evaluation, vol. 
80, pp. 5-26, 2014.

[84] Leeftink, A. G., Bikker, I. A., Vliegen, I. M. H. and Boucherie, R. J., "Multi-disciplinary planning in health care: A review," Health Systems, in press.

[85] Leeftink, A. G., Vliegen, I. M. H. and Hans, E. W., "Stochastic integer programming for multi-disciplinary outpatient clinic planning," Health Care Management Science, in press.

[86] Liang, B., Turkcan, A., Ceyhan, M. E. and Stuart, K., "Improvement of chemotherapy patient flow and scheduling in an outpatient oncology clinic," International Journal of Production Research, vol. 53, no. 24, pp. 7177-7190, 2015.

[87] Lillrank, P., "Integration and coordination in healthcare: An operations management view," Journal of Integrated Care, vol. 20, no. 1, pp. 6-12, 2012.

[88] Lodi, A. and Tubertini, P., "Pre-operative activities and operating theater planning in Emilia-Romagna, Italy," in Optimization in the Real World: Towards Solving RealWorld Optimization Problems, Fujisawa, K., Shinano, Y. and Waki, H., Eds. Tokyo: Springer Tokyo, 2016, pp. 115-137.

[89] Luscombe, R. and Kozan, E., "Dynamic resource allocation to improve emergency department efficiency in real time," European Journal of Operational Research, vol. 255, no. 2, pp. 593-603, 2016.

[90] Mackillop, W. J., "Killing time: The consequences of delays in radiotherapy," Radiotherapy and Oncology, vol. 84, no. 1, pp. 1-4, 2007.

[91] Mageshwari, G. and Kanaga, E. G. M., "Literature review on patient scheduling techniques," International Journal on Computer Science and Engineering, vol. 4, no. 3, pp. 397-401, 2012.

[92] Marinagi, C. C., Spyropoulos, C. D., Papatheodorou, C. and Kokkotos, S., "Continual planning and scheduling for managing patient tests in hospital laboratories," Artificial Intelligence in Medicine, vol. 20, no. 2, pp. 139-154, 2000.

[93] Matta, M. E. and Patterson, S. S., "Evaluating multiple performance measures across several dimensions at a multi-facility outpatient center," Health Care Management Science, vol. 10, no. 2, pp. 173-194, 2007.

[94] Mayer, G. G., Villaire, M. and Connell, J., "Ten recommendations for reducing unnecessary emergency department visits," Journal of Nursing Administration, vol. 35, no. 10 , pp. 428-430, 2005.

[95] Naidu, A., "Factors affecting patient satisfaction and healthcare quality," International Journal of Health Care Quality Assurance, vol. 22, no. 4, pp. 366-381, 2009.

[96] Oddi, A. and Cesta, A., "Toward interactive scheduling systems for managing medical resources," Artificial Intelligence in Medicine, vol. 20, no. 2, pp. 113-138, 2000.

[97] Paulussen, T. O., Jennings, N. R., Decker, K. S. and Heinzl, A., "Distributed patient scheduling in hospitals," in International Joint Conference on Artificial Intelligence, Acapulco, 2003, pp. 1224-1229.

[98] Paulussen, T. O., Zöller, A., Rothlauf, F., Heinzl, A., Braubach, L., Pokahr, A. and Lamersdorf, W., "Agent-based patient scheduling in hospitals," in Multiagent 
Engineering: Theory and Applications in Enterprises, Stefan, K., Herzog, O., Lockemann, P. and Spaniol, O., Eds. Springer Berlin Heidelberg, 2006, pp. 255-275.

[99] Pérez, E., Ntaimo, L., Malavé, C. O., Bailey, C. and McCormack, P., "Stochastic online appointment scheduling of multi-step sequential procedures in nuclear medicine," Health Care Management Science, vol. 16, no. 4, pp. 281-299, 2013.

[100] Petrovic, D., Morshed, M. and Petrovic, S., "Genetic algorithm based scheduling of radiotherapy treatments for cancer patients," in Proceedings of the Conference on Artificial Intelligence in Medicine in Europe, Verona, 2009, pp. 101-105.

[101] Petrovic, D., Castro, E., Petrovic, S. and Kapamara, T., "Radiotherapy scheduling," in Automated Scheduling and Planning: From Theory to Practice, Uyar, A. S., Ozcan, E. and Uruqhart, N., Eds. Berlin: Springer-Verlag Berlin-Heidelberg, 2013, pp. 155-189.

[102] Petrovic, D., Morshed, M. and Petrovic, S., "Multi-objective genetic algorithms for scheduling of radiotherapy treatments for categorised cancer patients," Expert Systems with Applications, vol. 38, no. 6, pp. 6994-7002, 2011.

[103] Petrovic, S., Leung, W., Song, X. and Sundar, S., "Algorithms for radiotherapy treatment booking," in Proceedings of the 25th Workshop of the UK Planning and Scheduling Special Interest Group, Nottingham, 2006, pp. 105-112.

[104] Petrovic, S. and Leite-Rocha, P., "Constructive and GRASP approaches to radiotherapy treatment scheduling," in Advances in Electrical and Electronics Engineering - Special Edition of the World Congress on Engineering and Computer Science 2008, San Francisco, 2008, pp. 192-200.

[105] Podgorelec, V. and Kokol, P., "Genetic algorithm based system for patient scheduling in highly constrained situations," Journal of Medical Systems, vol. 21, no. 6, pp. 417-427, 1997.

[106] Porter, M. E. and Lee, T. H., "The strategy that will fix health care," Harvard Business Review, pp. 50-70, 2013.

[107] Porter, M. E. and Teisberg, E. O., "How physicians can change the future of health care," Journal of American Medicine Association, vol. 297, no. 10, pp. 1103-1111, 2007.

[108] Powell, W. B., "What you should know about approximate dynamic programming," Naval Research Logistics, vol. 56, no. 3, pp. 239-249, 2009.

[109] Ragaz, J., Olivotto, I. A., Spinelli, J. J., Phillips, N., Jackson, S. M., Wilson, K. S., Knowling, M. A., Coppin, C. M. L., Weir, L., Gelmon, K., Le, N., Durand, R., Coldman, A. J. and Manji, M., "Locoregional radiation therapy in patients with high-risk breast cancer receiving adjuvant chemotherapy: 20-year results of the British Columbia randomized trial," Journal of the National Cancer Institute, vol. 97, no. 2, pp. 116-126, 2005.

[110] Raschendorfer, I. M. and Hamacher, H. W., "Hierarchical edge colorings and rehabilitation therapy planning in Germany," in Proceedings of the EURO Summer Institute on Operational Research Applied to Health in a Modern World, Bard, 2014.

[111] Rezaeiahari, M. and Khasawneh, M. T., "An optimization model for scheduling patients in destination medical centers," Operations Research for Health Care, vol. 15, pp. 68$81,2017$. 
[112] Riff, M.-C., Cares, J. P. and Neveu, B., "RASON: A new approach to the scheduling radiotherapy problem that considers the current waiting times," Expert Systems with Applications, vol. 64, pp. 287-295, 2016.

[113] Romero, H. L., Dellaert, N. P., van der Geer, S., Frunt, M., Jansen-Vullers, M. H. and Krekels, G. A. M., "Admission and capacity planning for the implementation of onestop-shop in skin cancer treatment using simulation-based optimization," Health Care Management Science, vol. 16, no. 1, pp. 75-86, 2013.

[114] Saadani, N. E. H., Bahroun, Z. and Bouras, A., "A linear mathematical model for patients' activities scheduling on hospital resources," in Proceedings for the 2014 International Conference on Control, Decision and Information Technologies, Metz, 2014, pp. 74-80.

[115] Sadki, A., Xie, X. and Chauvin, F., "Patients assignment for an oncology outpatient unit," in IEEE International Conference on Automation Science and Engineering, Toronto, 2010, pp. 891-896.

[116] Samudra, M., Van Riet, C., Demeulemeester, E., Cardoen, B., Vansteenkiste, N. and Rademakers, F. E., "Scheduling operating rooms: Achievements, challenges and pitfalls," Journal of Scheduling, vol. 19, no. 5, pp. 493-525, 2016.

[117] Sauré, A., Patrick, J., Tyldesley, S. and Puterman, M. L., "Dynamic multi-appointment patient scheduling for radiation therapy," European Journal of Operational Research, vol. 223, no. 2, pp. 573-584, 2012.

[118] Schaefer, A. J., Bailey, M. D., Shechter, S. M. and Roberts, M. S., "Modeling medical treatment using Markov decision processes," in Operations Research and Health Care: A handbook of Methods and Applications, Brandeau, M. L., Sainfort, F. and Pierskalla, W. P., Eds. Boston: Springer, Boston, 2004, pp. 593-612.

[119] Schimmelpfeng, K., Helber, S. and Kasper, S., "Decision support for rehabilitation hospital scheduling," OR Spectrum, vol. 34, no. 2, pp. 461-489, 2012.

[120] Sevinc, S., Sanli, U. A. and Goker, E., "Algorithms for scheduling of chemotherapy plans," Computers in Biology and Medicine, vol. 43, no. 12, pp. 2103-2109, 2013.

[121] Skinner, W., "The focused factory,” Harvard Business Review, pp. 113-121, 1974.

[122] Sowle, T., Gardimi, N., Vazquez, F. V. A., Pérez, E., Jimenez, J. A. and De Pagter, L., "A simulation-IP based tool for patient admission services in a multi-specialty outpatient clinic," in Proceedings of the 2014 Winter Simulation Conference, Savannah, 2014, pp. 1186-1197.

[123] Stoffels, R. A. M. R., Cooperation among medical specialists: "Pain" or "Gain"?, PhD thesis. Groningen: University of Groningen, 2008.

[124] Suss, S., Bhuiyan, N., Demirli, K. and Batist, G., "Achieving level patient flow in an outpatient oncology clinic," IISE Transactions on Healthcare Systems Engineering, in press.

[125] Tsai, P.-F. J. and Teng, G.-Y., "A stochastic appointment scheduling system on multiple resources with dynamic call-in sequence and patient no-shows for an outpatient clinic," European Journal of Operational Research, vol. 239, no. 2, pp. 427-436, 2014.

[126] Turkcan, A., Zeng, B. and Lawley, M., "Chemotherapy operations planning and 
scheduling," IIE Transactions on Healthcare Systems Engineering, vol. 2, no. 1, pp. 3149, 2012.

[127] Valentijn, P. P., Boesveld, I. C., van der Klauw, D. M., Ruwaard, D., Struijs, J. N., Molema, J. J. W., Bruijnzeels, M. A. and Vrijhoef, H. J., "Towards a taxonomy for integrated care: A mixed-methods study," International Journal of Integrated Care, vol. $15,2015$.

[128] Vanberkel, P. T., Boucherie, R. J., Hans, E. W., Hurink, J. L. and Litvak, N., "A survey of health care models that encompass multiple departments," International Journal of Health Management and Information, vol. 1, no. 1, pp. 37-69, 2009.

[129] Vasilakis, C., Sobolev, B. G., Kuramoto, L. and Levy, A. R., "A simulation study of scheduling clinic appointments in surgical care: Individual surgeon versus pooled lists," Journal of the Operational Research Society, vol. 58, no. 2, pp. 202-211, 2007.

[130] Vermeulen, I. B., Bohte, S., Elkhuizen, S. G., Bakker, P. and La Poutré, H., "Decentralized online scheduling of combination-appointments in hospitals," in Proceedings of the International Conference on Automated Planning and Scheduling, Sydney, 2008, pp. 372-379.

[131] Vermeulen, I. B., Bohte, S. M., Somefun, K. and La Poutré, H., "Multi-agent Pareto appointment exchanging in hospital patient scheduling," Service Oriented Computing and Applications, vol. 1, no. 3, pp. 185-196, 2007.

[132] Vieira, B., Hans, E. W., Van Vliet-Vroegindeweij, C., van de Kamer, J. and van Harten, W., "Operations research for resource planning and -use in radiotherapy: A literature review," BMC Medical Informatics and Decision Making, vol. 16, 2016.

[133] Vissers, J. M. H., Adan, I. J. B. F. and Dellaert, N. P., "Developing a platform for comparison of hospital admission systems: An illustration," European Journal of Operational Research, vol. 180, no. 3, pp. 1290-1301, 2007.

[134] Vlah, S., Lukač, Z. and Pacheco, J., "Use of VNS heuristics for scheduling of patients in hospital," Journal of the Operational Research Society, vol. 62, no. 7, pp. 1227-1238, 2011.

[135] Van De Vrugt, M., Efficient healthcare logistics with a human touch, PhD thesis. Enschede: University of Twente, 2016.

[136] White, D. L., Froehle, C. M. and Klassen, K. J., "The effect of integrated scheduling and capacity policies on clinical efficiency," Production and Operations Management, vol. 20, no. 3, pp. 442-455, 2011.

[137] Xiaofeng, H., Hui, W., Shaoming, Z., Xing, D. and Ye, J., "Scheduling outpatients in hospital examination departments," in 2009 IEEE International Conference on Industrial Engineering and Engineering Management, Hong Kong, 2009, pp. 335-338.

[138] Zhao, L., Chien, C.-F. and Gen, M., "A bi-objective genetic algorithm for intelligent rehabilitation scheduling considering therapy precedence constraints," Journal of Intelligent Manufacturing, in press.

[139] Zonderland, M. E., Appointment planning in outpatient clinics and diagnostic facilities. Boston: Springer, 2014.

[140] Zonderland, M. E., Boucherie, R. J. and Al Hanbali, A., "Appointments in care 
pathways: The Geox/D/1 queue with slot reservations," Queueing Systems, vol. 79, no. 1, pp. 37-51, 2014. 